\title{
ist \\ A tecnologia como problema filosófico: três enfoques
}

\author{
Alberto Gupani
}

\begin{abstract}
茴
RESUMO

O estudo filosófico da tecnologia é relativamente recente e diversificado, conforme diferentes orientações teóricas e suas correspondentes atitudes sociais. Apesar dessa heterogeneidade, ou precisamente graças a ela, a filosofia da tecnologia nos ajuda a reconhecer a tecnologia como dimensão da vida humana, e não apenas como um evento histórico. É o que pretendo mostrar apresentando três modos de investigar filosoficamente a tecnologia: os de Mario Bunge, Albert Borgmann e Andrew Feenberg, que representam, respectivamente, uma perspectiva analítica, uma abordagem fenomenológica e um exame inspirado na Escola de Frankfurt. O intuito principal deste artigo é a divulgação dessas investigações, pouco conhecidas entre nós. No entanto, ele inclui uma breve apreciação crítica das mesmas.
\end{abstract}

PaLAVRaS- $\mathrm{CHAVE} \bullet$ Filosofia da tecnologia. Mario Bunge. Albert Borgmann. Andrew Feenberg.

\section{INTRODUÇÃO}

A filosofia da tecnologia é uma disciplina relativamente recente, se comparada com as restantes disciplinas filosóficas, incluída a filosofia da ciência. ${ }^{\mathbf{1}}$ Trata-se de um campo de estudos mais heterogêneo do que sua denominação faria supor, pois a própria definição do seu objeto não é unânime. Por outra parte, embora não seja possível ignorar a relação da tecnologia contemporânea com a técnica de épocas e culturas anteriores, e a diferença entre ambas seja devida, em grande medida, à presença da ciência experimental na tecnologia, nem todos os estudiosos concebem a tecnologia como (mera) ciência aplicada e nem todos admitem uma continuidade de propósitos entre a técnica e a tecnologia. Além disso, a reflexão filosófica que recai sobre a tecnologia corresponde a

1 Embora não faltem antecedentes no século XIX e na primeira metade do xx, seu desenvolvimento institucional (incluindo revistas e congressos específicos) data das últimas décadas do século xx. Cf. Mitcham, 1994, cap. 1. 
diferentes estilos de pensamento. ${ }^{2}$ Apesar dessa heterogeneidade, a disciplina encontra a sua unidade na preocupação por um aspecto ou dimensão da vida humana impossível de ignorar e particularmente marcado na sociedade contemporânea: a atividade eficiente, racionalmente regrada, no que diz respeito às suas motivações, desenvolvimento, alcance e conseqüências.

A compreensão dessa dimensão da vida leva-nos a lembrar que a técnica, como capacidade humana de modificar deliberadamente materiais, objetos e eventos (chegando a produzir elementos novos, não existentes na natureza), define o ser humano como homofaber. ${ }^{3}$ Ofazer (ou melhor, o saberfazer) difere de outras capacidades humanas como a de contemplar a realidade (literal ou mentalmente), agir (no sentido de adotar decisões responsáveis), experimentar sentimentos (que chegam a ser muito sofisticados, como o fascínio de uma obra de arte) e expressar-se (sobretudo, manifestar a própria identidade, as próprias idéias, os próprios anseios) mediante uma linguagem articulada, particularmente a enunciativa. Esse caráter da técnica deve ser levado em consideração ao entender a tecnologia como modo de vida, sobretudo na medida em que esse modo de vida afeta outros modos em que podem prevalecer aquelas outras capacidades humanas antes mencionadas.

A seguir, apresentarei três enfoques da tecnologia, cada um dos quais representa uma corrente filosófica contemporânea relevante. O primeiro deles é o enfoque analítico de Mario Bunge, reconhecido como um dos fundadores da disciplina. Bunge não é, certamente, um filósofo "analítico" em sentido próprio do termo, mas a sua classificação aqui corresponde ao fato de que a análise conceitual tem um papel preponderante na sua filosofia. O segundo enfoque escolhido é o da fenomenologia, aqui representada pelo livro Technology and the character of contemporary life (1984) de Albert Borgmann. Finalmente, apresentarei o enfoque de Andrew Feenberg, que analisa a tecnologia a partir da filosofia crítica da Escola de Frankfurt em sua obra Transforming technology (2002). A minha exposição dos enfoques mencionados será seguida por algumas considerações críticas.

\footnotetext{
2 Mitcham registra também a polarização entre a "filosofia da tecnologia dos engenheiros" (vale dizer, dos autores de formação científica ou tecnológica, como Bunge) e a "filosofia da tecnologia dos humanistas" (filósofos ou escritores de cultura clássica, como Heidegger ou Mumford) (cf. Mitcham, 1994, cap. 1 e 2). Os primeiros são geralmente defensores e os segundos, críticos da tecnologia.

3 Ortega y Gasset, um dos primeiros autores a refletir sobre a técnica, observou que o homem não se limita a adequar-se à natureza, mas adapta a natureza a suas necessidades ou propósitos, criando o supérfluo (cf. Ortega y Gasset, 1965). De resto, a técnica talvez responda a uma inclinação do organismo a poupar esforços desnecessários (cf. Ladrière, 1979, p. 84).
} 


\section{A perspegtiva analítica de Mario Bunge4}

Adotando uma distinção do historiador Lewis Mumford, Bunge entende por técnica o controle ou a transformação da natureza pelo homem, o qual faz uso de conhecimentos pré-científicos. A tecnologia, por sua vez, consiste na técnica de base científica, num sentido que precisaremos mais adiante.

Quer se trate de técnica quer de tecnologia, o que está em jogo é uma atividade consistente na produção de algo artificial, de um "arte-fato". O artefato não precisa ser todavia uma coisa (por exemplo, uma bicicleta, ou um remédio), podendo tratar-se também da modificação do estado de um sistema natural (por exemplo, desviar ou represar o curso de um rio), ou bem da transformação de um sistema (por exemplo, ensinar alguém a ler). Em todos os casos, a ação técnica - uma forma de trabalho, para Bunge - opera utilizando recursos naturais (como empregar o cérebro próprio para resolver um problema de maneira metódica, usar troncos de árvore para construir uma cabana etc.), transformando-os (produzir tecidos com base no linho, domesticar animais etc.), ou bem reunindo elementos naturais para dar origem a algo inédito (sintetizar moléculas, organizar pessoas numa firma comercial etc.).

Algo artificial é, segundo Bunge, "toda coisa, estado ou processo controlado ou feito deliberadamente com ajuda de algum conhecimento aprendido, e utilizável por outros" (Bunge, 1985a, p. 33-4). Ou também pode dizer-se que: "Um sistema concreto (material) é um artefato se, e somente se, cada um dos seus estados depende de estados prévios ou concomitantes de algum ser racional" (Bunge, 1985b, p. 223).

Cabe observar que o "artefato" pode eventualmente ser algo social, como quando se organiza uma equipe esportiva, pode tratar-se do resultado de um serviço (por exemplo, a cura de pacientes) e, finalmente, pode consistir em algo julgado como negativo (como as armas atômicas).

Além da noção de artefato, a técnica e a tecnologia caracterizam-se pela existência de uma planificação, ainda que mínima. Técnica e tecnologia supõem um objetivo preciso. $\mathrm{O}$ artefato é concebido (antecipado), e se procura sistematicamente os meios de produzi-lo. Para tanto, a técnica, como a tecnologia, supõem conhecimentos, já disponíveis ou novos. A técnica serve-se do saber vulgar tradicional, eventualmente impregnado de saber científico que não é reconhecido como tal. A tecnologia recorre explicitamente ao saber científico (dados, leis, teorias), de um modo que ainda iremos especificar. Para a produção técnica ou tecnológica os elementos são vistos como recur-

4. Bunge é bem conhecido como filósofo da ciência. Ensinou na McGill University (Canadá). Na sua vasta produção, destaca-se o Treatise on basic philosophy em 8 volumes. 
sos, não sendo apreciados apenas pelas suas qualidades inerentes. 5 Técnica e tecnologia implicam, portanto, valores (na forma genérica de que "tal coisa é útil ou adequada para tal outra"). Finalmente, a produção técnica ou tecnológica contém regras, ou seja, instruções "para realizar um número finito de atos numa ordem dada e com um objetivo também dado", constituindo assim "normas estáveis do comportamento humano com sucesso" (Bunge, 1969, p. 694). Sem elas, nenhum artefato funcionaria ou seria utilizável "por outros", como estabelece a sua definição. No entanto, as regras são necessárias sobretudo porque o objeto artificial deve ser eficiente, desempenhando a sua função da maneira mais econômica possível. ${ }^{6}$ Por conseguinte, o esquema geral da ação técnica é:

Se há de se conseguir $y$ no momento $t$ com probabilidade $p$, então deve fazer-se $x$ no momento $t$ (Bunge, 1969, p. 7०3).

Assim analisada, a ação técnica é, essencialmente, ação racional orientada a garantir, poder-se-ia dizer, seu próprio sucesso.

Se a técnica acompanhou (e possibilitou) o desenvolvimento da humanidade ao longo da maior parte da história, o surgimento da tecnologia foi condição de uma aceleração do progresso humano. Isso se deve a que a inovação é, dentro da técnica précientífica, um processo dificultado pela inércia da vida tradicional. Comenta Bunge: "A práxis, a menos que seja guiada pela pesquisa científica, é extremadamente limitada e conservadora" (Bunge, $1985 \mathrm{~b}$, p. 311). Desde um ponto de vista sistemático, a tecnologia surge na medida em que, ou bem se indaga a fundamentação teórica das regras técnicas, ou bem se busca aplicar conhecimentos científicos à solução de problemas práticos. A tecnologia pode, assim, ser definida como

O campo de conhecimento relativo ao desenho de artefatos e à planificação da sua realização, operação, ajuste, manutenção e monitoramento à luz do conhecimento científico. Ou, resumidamente: o estudo científico do artificial (Bunge, 1985 b, p. 231).

5 Para o olhar tecnológico, afirma Bunge, os objetos, processos e eventos reais se classificam em recursos, produtos (artefatos), e o resto, ou seja, "o conjunto das coisas inúteis, abrangendo os produtos residuais não recicláveis”. Cff. Bunge, 1980, p. 199 .

6 Ao interesse na eficiência e na economia, vinculam-se outras propriedades desejadas do produto técnico (e particularmente, do tecnológico), tais como a padronização, a segurança, a confiabilidade e a rapidez. 
A caracterização da tecnologia como "campo de conhecimento" obedece a que, para Bunge, não existe tecnologia onde o homem se limita a aplicar um saber-fazer, ou a servir-se de artefatos sem se perguntar pela sua base teórica nem procurar o seu aperfeiçoamento. Em todo caso, essa é a conduta do mero técnico contemporâneo, mas não do tecnólogo (sendo o engenheiro seu protótipo), cuja atividade é sempre em alguma medida teórica e criativa. Isso se adverte melhor considerando o aspecto que assumem, no caso da tecnologia, as caraterísticas gerais da técnica antes mencionadas.

O caráter deliberado da invenção técnica é reforçado na tecnologia, que supõe o desenho e a planificação metódicos do artefato a ser produzido. O desenho (ou projeto) tecnológico é "a representação antecipada de um artefato com o auxílio de algum conhecimento científico". O seu propósito é criar sistemas funcionais, "sistemas que desempenhem efetiva e eficientemente certas funções úteis para determinadas pessoas" (Bunge, 1985b, p. 226). Entre esses sistemas, destacam-se as máquinas, sistemas não viventes projetados para auxiliar em algum tipo de trabalho. Já a planificação consiste em articular uma seqüência de tarefas (ou "sub-rotinas") destinadas a alcançar o objetivo proposto, que pode ser visto como a modificação introduzida num determinado estado de um sistema, para que alcance outro estado desejado.

Em todo caso, o desenho e a planificação tecnológicos repousam no conhecimento científico. Trata-se de leis ou fragmentos de teorias que devem ser traduzidas em "enunciados nomo-pragmáticos", que fundamentam, por sua vez, as regras práticas. Num exemplo simples: a lei ("enunciado nomológico") que afirma "Aágua ferve a $100^{\circ}$ celsius" fundamenta o enunciado nomo-pragmático "Se a água é esquentada a $100^{\circ} \mathrm{C}$, então ela ferve", o qual, por sua vez, fundamenta regras tecnológicas tais como: "Para ferver água, esquente-a até $100^{\circ} \mathrm{C}$ ", "Para evitar que a água ferva, mantenha-se sua temperatura abaixo de $100^{\circ} \mathrm{C}$ " etc.

Todavia, a tecnologia não se reduz, para Bunge, à utilização do conhecimento científico, mas implica na busca de um conhecimento específico, o que dá origem a teorias tecnológicas, que podem ser de dois tipos: substantivas, vale dizer aquelas que fornecem conhecimento sobre os objetos da ação (por exemplo, uma teoria sobre o vôo), ou ainda operativas, isto é, aquelas que versam sobre as ações de que depende o funcionamento dos artefatos (por exemplo, uma teoria das decisões ótimas sobre a distribuição do trânsito aéreo numa região). As teorias substantivas são aplicações de teorias científicas a situações reais (a teoria do vôo resulta de aplicar a dinâmica dos fluidos). As teorias operativas são, por assim dizer, mais diretamente tecnológicas, pois enfocam desde o início a ação que se tem em vista, por exemplo, o complexo homemmáquina em situações aproximadamente reais. Em tais casos, a tecnologia pode combinar conhecimento ordinário, elementos das ciências formais e certos conhecimentos especializados não científicos (por exemplo, práticas de pilotagem) com algumas 
das tecnologias que Bunge denomina gerais (como a teoria da decisão). Mas em conjunto, a tecnologia comparte com a ciência o método, ou seja, a estratégia geral da pesquisa. ${ }^{7}$ Por outra parte, a distinção entre dois tipos de tecnologia não é uma dicotomia: as tecnologias são predominantemente substantivas ou operativas, conforme o caso.

Quando uma teoria científica é aplicada tecnologicamente ou transformada em teoria tecnológica (por exemplo, a hidrodinâmica transformada em hidráulica), resulta ao mesmo tempo mais rica e mais pobre que quando funciona dentro da ciência pura, explica Bunge. Ela é mais rica desde um ponto de vista prático, porque em vez de limitar-se a prever o que poderá ocorrer em determinadas circunstâncias, a teoria averigua o que se deve fazer para modificar o curso dos eventos. Simultaneamente, desde o ponto de vista conceitual, são teorias mais pobres no sentido de que são menos profundas. Geralmente, o tecnólogo se conforma com teorias fenomenológicas, vale dizer, aquelas que não penetram (ou não penetram demasiado) no funcionamento interno dos sistemas que se pretende modificar, limitando-se a levar em consideração as variáveis externas (cf. Bunge, 1969, p. 685). Com outras palavras, dá-se um empobrecimento conceitual das teorias científicas no seu uso tecnológico, pois em função do seu propósito eminentemente prático, o tecnólogo geralmente esquematiza e simplifica o domínio de que se ocupa. 8

Pela razão antes apontada, entre outras, a tecnologia, para Bunge, não deve ser exaltada às custas da ciência pura. Não obstante, a tecnologia tem um grande valor, pois se a técnica encarna a ação racional endereçada a garantir seu próprio sucesso, a tecnologia pode ser vista como a concretização da ação plenamente racional (cf. Bunge, 1969, p. 684; 1985b, p. 239). ${ }^{9}$ E quanto mais racionais forem o pensamento e a ação humanos, melhor poderá ser, em princípio, a sua vida - sustenta Bunge, conhecido defensor da tradição iluminista. Essa convicção explica que ele possa classificar como tecnologias atividades tais como a medicina, a administração ou a pedagogia, confiando em que todos os problemas práticos humanos possam ser formulados tecnologicamente, ou ter uma solução adequada que se fundamente na ciência e na tecnologia. Nesse sentido, o otimismo bungeano chega a supor possível uma "engenharia social", ${ }^{\circ}$

\footnotetext{
7 Bunge defende a existência de uma estratégia ou disciplina geral de toda pesquisa, que corresponde ao método hipotético-dedutivo descrito em forma mais detalhada em Bunge, 1969, Cap. 1; 1980, Cap. 2.

8 Não obstante, Bunge adverte que o "autêntico" tecnólogo "não evitará as teorias profundas e complexas quando prometam sucesso. Por exemplo, utilizará a teoria quântica dos sólidos para projetar componentes de equipamentos de rádio ou de computadores, e a genética para obter variedades de milho de maior rendimento" (Bunge, 1980, p. 194).

9 Por tal razão, a filosofia da tecnologia deve prolongar-se numa tecno-praxiologia, ramo da reflexão filosófica postulado por Bunge para estudar sistematicamente a ação guiada pela tecnologia (cf. Bunge, 1980, p. 205).

10 A expressão, como é notório, foi usada já por K. Popper.
} 
base de políticas sociais progressistas. Uma tal engenharia consistiria em colocar todos os recursos científicos possíveis (principalmente, é óbvio, científico-sociais) ao serviço de problemas tais como a escassez de recursos, a fome, a superpopulação, a criminalidade, o militarismo etc. (cf. Bunge, 1985b, p. 286). A engenharia social, para ser efetiva, deveria ser sistêmica (e não fragmentária), ${ }^{11}$ produzida por equipes interdisciplinares e discutida democraticamente.

O que acaba de ser dito não significa que Bunge acredite que a tecnologia seja ou tenha sido sempre benéfica. Indiscutivelmente, o desenvolvimento tecnológico tem causado inúmeros males e problemas, posto que até as invenções vistas como positivas comportam circunstancialmente conseqüências negativas. ${ }^{12}$ Como depende em sua produção e controle dos seres humanos (Bunge rejeita a idéia de que seja autônoma), a tecnologia está assim sujeita aos mais variados interesses e propósitos. Muitos dos excessos e extravios da tecnologia são para ele derivados do código moral nela implícito. Trata-se de um código que separa o homem do resto da natureza, autorizando-o a submetê-la e isentando-o de responsabilidades (cf. Bunge, 1980, p. 203). Ele considera particularmente nefasta a noção, tão difundida, de que a tecnologia seja axiologicamente neutra. Para combatê-la, Bunge defende uma ética que aponte as responsabilidades naturais e sociais da inovação tecnológica. E, sobretudo, defende a necessidade de uma democracia integral, participativa e cooperativa ("holotecnodemocracia"), em que o desenvolvimento tecnológico pudesse estar verdadeiramente a serviço de todos (cf. Bunge, 1989).

\section{A abordagem fenomenológiga de Albert Borgmann}

Para Borgmann, ${ }^{\mathbf{1 3}}$ "tecnologia” não designa uma forma de técnica, mais evoluída e potente graças à sua associação com a ciência, como no caso de Bunge, mas um modo de vida próprio da Modernidade. A tecnologia é o modo tipicamente moderno de o homem lidar com o mundo, um "paradigma" ou "padrão" caraterístico e limitador da existência, intrínseco à vida quotidiana. Tão intrínseco que ele passa, por isso mesmo, despercebido. No entanto, o surgimento e o poder desse padrão constituem para Borgmann "o evento de maiores conseqüências do período moderno", estando seu livro

11 Bunge é um notório defensor do enfoque sistêmico em ciência e filosofia.

12 O automóvel aumentou enormemente a poluição ambiental e reforçou o individualismo; a "revolução verde" ampliou a distância entre pobres e ricos; a televisão torna as crianças passivas etc. (os exemplos são de Bunge).

13 Borgmann é professor da Universidade de Montana (EUA), e autor de outras obras como Crossing the postmodern divide (1992) e Holding on to reality: the nature of information and the turn of the millennium (1999). 
dedicado a explorá-lo fenomenologicamente, bem como a propor um princípio de solução para o problema que a tecnologia representa (cf. Borgmann, 1984, p. 1).

A escolha do enfoque fenomenológico (lato sensu) por parte de Borgmann devese à sua convicção de que outros enfoques perdem de vista (ou não reconhecem) a especificidade da tecnologia. As teorias instrumentais (isto é, aquelas que vêem a tecnologia como um meio ao serviço dos propósitos humanos) são para Borgmann superficiais, e as teorias substancialistas (as que acreditam que a tecnologia seja autônoma) deixam "obscuro", na sua opinião, o caráter da tecnologia. Existem, ainda, teorias "pluralistas", que insistem na multiplicidade de fatores a que responde a tecnologia, porém a atenção para essa multiplicidade faz que percam de vista o esquema básico que dá sentido ao conjunto. A análise da tecnologia por parte das ciências sociais, por sua vez, lhe parece "inconclusiva", pois a complexidade dos fenômenos sociais, em que a tecnologia está inserida, faz que toda teoria seja, apesar de precisa (e justamente por isso), ambígua. O estudo fenomenológico, destinado a mostrar o seu objeto, deve, no entanto, ser "testado e elaborado contra o trabalho pertinente em filosofia e, especialmente, em ciências sociais" (Borgmann, 1984, p. 5) ${ }^{\mathbf{1 4}}$

Para Borgmann, a tecnologia e os seus problemas nunca serão compreendidos enquanto forem considerados como conseqüências de fatores sociais, políticos ou ecológicos. Deve-se reconhecer na tecnologia um fenômeno básico, que tem sua chave na existência dos dispositivos (devices) que nos fornecem produtos (commodities), ou seja, bens e serviços, quer se trate do aquecedor elétrico, que nos dá calor, do automóvel, que nos permite deslocamento rápido e relativamente livre, ou do aparelho de televisão, que põe ao nosso alcance informação e diversão. Como veremos, à noção de dispositivo se opõe a noção de coisa, sendo os dispositivos e as coisas os paradigmas de duas formas diferentes de vida humana; contraste através do qual Borgmann aspira a mostrar a verdadeira índole da tecnologia.

Os dispositivos são essencialmente um meio (algo-para), ${ }^{\mathbf{1 5}}$ sendo necessário distinguir ainda entre a maquinaria do dispositivio e a sua função. Ao passo que esta última é conhecida do usuário, a primeira é geralmente incompreendida e até incompreensível para ele (pensemos, por exemplo, na ignorância com relação à maquinaria

14 Explicar, afirma Borgmann, é "fornecer compreensão". As ciências naturais explicam apoditicamente, isto é, a partir de leis e condições iniciais ou de contorno. Também o fazem as ciências sociais. Ambas, no entanto, carecem de poder para determinar o que é relevante para ser explicado. Isto deve ser explicado de outra maneira, "dêitica" (mostrativa). Uma terceira forma de explicação é a "paradigmática”, isto é, a que revela um padrão que dá sentido a um determinado âmbito de objetos e eventos. O enfoque escolhido por Borgmann para tratar da tecnologia combina o segundo e o terceiro modos de explicação. Cf. Borgmann, 1984, cap. 12. 15 A influência de Heidegger (Sein und Zeit, 1967) nesta análise de Borgmann é evidente. 
de um computador, ainda que saibamos usá-lo bem). Mediante a sua função, um dispositivo nos "alivia" (disburdens) de um esforço, nos liberta de um "peso", resolve alguma dificuldade. Por outra parte, diferentes dispositivos podem nos fornecer o mesmo produto (podemos nos aquecer mediante diversos tipos de sistemas), vale dizer que os dispositivos têm equivalentes funcionais. Sobretudo, o dispositivo caracterizase por tornar disponível o produto correspondente. Essa disponibilidade significa que os produtos podem ser consumidos de maneira instantânea, ubíqua, segura e fácil. Basta lembrar o alívio de satisfazer qualquer necessidade (de luz, de música, de informação) apenas apertando um botão de aparelhos que estão sempre “à mão". A disponibilidade encerra ainda outras caraterísticas, como se pode apreciar na seguinte citação:

Uma forma de tornar disponíveis os produtos é torná-los descartáveis. Não é apenas desnecessário, mas impossível manter e reparar guardanapos de papel, latas de conserva, canetas esferográficas ou qualquer outro produto destinado a ser usado uma vez. Outro modo da disponibilidade é tornar desnecessário o cuidado dos produtos. Os talheres de aço inoxidável não requerem polimento, os pratos de plástico não precisam ser manipulados com cuidado. Em outros casos, a manutenção e a reparação tornam-se impossíveis por causa da sofisticação do produto [...] os microcomputadores estão sendo usados cada vez mais porque vão se tornando "amigáveis", isto é, fáceis de operar e compreender. Mas esse caráter "amigável" é precisamente o sinal do quanto se tem tornado grande o hiato entre a função acessível a todos e a maquinaria conhecida por quase ninguém... (Borgmann, 1984, p. 47).

Os produtos e seu consumo constituem "a meta declarada do empreendimento tecnológico", assegura Borgmann. Essa meta foi proposta pela primeira vez no início da Modernidade, como expectativa de que o homem poderia dominar a natureza. No entanto, essa expectativa, convertida em programa anunciado por pensadores como Descartes e Bacon e impulsionado pelo Iluminismo, não surgiu "de um prazer de poder", "de um mero imperialismo humano", mas da aspiração de libertar o homem (da fome, da insegurança, da dor, da labuta) e de enriquecer sua vida, física e culturalmente. Sem levar em consideração esse afã de libertação não se pode entender o padrão da tecnologia que, à maneira de um molde, foi dando forma à sociedade humana nos países industrialmente desenvolvidos. Não basta, portanto, para entender a tecnologia, atentar para o seu aspecto de natureza dominada, nem à sua associação com a ciência. $\mathrm{O}$ avanço científico e a sua aplicação a finalidades práticas são imprescindíveis para que exista a maioria das invenções tecnológicas, mas a ciência, por si mesma, não pode fornecerlhe um rumo nem explicar por que a tecnologia tem chegado a ser um modo de vida. 
Esse modo de vida implica a tendência a reduzir todo e qualquer problema a uma questão de relação entre meios e fins. Reciprocamente, o mundo dos dispositivos é um mundo de meros meios, sem fins últimos, o que constitui uma novidade na história humana. Isto é muito importante para se entender, segundo Borgmann, a diferença entre a técnica tradicional e a tecnologia. Ao passo que na técnica toda relação meiofim estava inserida em um contexto (social, cultural, ecológico), na tecnologia a relação meio-fim vale universalmente, com independência dos contextos concretos. Enquanto a lareira tradicional, ainda que sendo um meio para aquecer o lar, estava inserida na trama de relações entre os membros da família, supunha o trabalho necessário para acendê-la e mantê-la, e incentivava a reunião da família e o cultivo dos costumes, o aquecedor moderno se reduz à sua função de fornecer calor, não importa para quem, nem em quais circunstâncias. Os dispositivos carecem de contexto, podendo ser usados para (relativamente) diversos fins e combinados entre si sem muitas restrições. Os dispositivos são assim ambíguos. Em correspondência com essas propriedades dos dispositivos, a nossa relação para com eles é de falta de compromisso (engagement). ${ }^{\mathbf{1 6}}$

Em nenhum aspecto da nossa vida é tudo isso mais evidente - comenta Borgmann - do que na propaganda, ou seja, no apelo constante e sistemático ao consumo de dispositivos. Estes últimos aparecem na propaganda nas mais insólitas combinações (carros associados a obras de arte, paisagens acompanhadas de músicas, símbolos religiosos misturados a figuras sensuais etc.), o que acentua a superficialidade dos dispositivos. $\mathrm{Na}$ propaganda, eles como que se escondem, deixando-nos face aos produtos de que são veículos, e com os quais somos continuamente tentados. De resto, para Borgmann, a propaganda não cria a cultura de consumidores, mas a regula e a põe de relevo.

[...] o universo da propaganda é inteiramente um universo de produtos e consumo. Ela destila o aspecto frontal da tecnologia em forma ideal e assim apresenta o lado técnico e distintivo da nossa época. Deste modo, ela superou a arte como a apresentação arquetípica daquilo de que trata a nossa época. Na propaganda, a promessa da tecnologia é apresentada ao mesmo tempo em pureza e concretamente, e, portanto, da maneira mais atraente. Problemas e ameaças entram apenas como pano de fundo para destacar as benções da tecnologia. Assim, nos encontramos definidos arquetipicamente nas propagandas. Elas fornecem uma força estabilizadora e orientadora na complexidade da sociedade tecnológica ainda em desenvolvimento (Borgmann, 1984, p. 55).

16 Essa falta de compromisso se evidencia, por exemplo, na facilidade com que substituímos um artifício que não mais funciona (ou não mais está na moda) por um outro equivalente, ou "melhor". 
Mas - e isto é o decisivo - o consumo universal de produtos é a realização da promessa da tecnologia. O sonho de uma vida humana menos penosa e mais rica tem-se transformado numa cultura que visa apenas o lazer derivado de consumir cada vez mais produtos tecnológicos. A vida dentro do "paradigma da tecnologia" resulta sem rumo e, no entanto, impositiva.

Todas as caraterísticas antes descritas da vida no "paradigma do dispositivo" (device paradigm) ressaltam quando consideramos, por contraste, o que são as coisas que podem "focar" ou centrar a nossa existência, as "coisas e práticas focais".

A palavra latina focus significa a lareira, o lugar do fogo [...] numa casa prétecnológica, a lareira constituía um centro de calor, de luz, de práticas diárias. Para os romanos, o focus era sagrado, o lugar onde residiam os deuses do lar. $\mathrm{Na}$ Grécia antiga, um bebê era verdadeiramente incorporado à família e à casa quando era transportado em torno da lareira e colocado diante dela. A união de um matrimônio romano era santificada na lareira. E ao menos nas épocas primitivas, os mortos eram enterrados junto à lareira. A família comia junto à lareira e fazia sacrifícios aos deuses do lar antes e depois da comida. A lareira sustentava, ordenava e centrava a casa e a família. [...] [hoje] a lareira amiúde tem uma localização central na casa. Seu fogo é agora simbólico, dado que raramente fornece suficiente calor. Mas a irradiação, os sons e a fragrância do fogo vivo consumindo lenhos que são quebrados, amontoados e sentidos nas suas veias têm retido a sua força. Não há mais imagens dos deuses ancestrais situadas junto ao fogo, mas há amiúde fotografias de entes queridos sobre a lareira, coisas preciosas da história da família, ou um relógio, medindo o tempo (Borgmann, 1984, p. 196).

De maneira análoga, tocar um instrumento musical (melhor, se for em companhia de outras pessoas), caminhar em contato com a natureza relativamente virgem, comer em família ou pescar por esporte, constituem outros tantos exemplos de "práticas focais" que dirigem a nossa atenção para coisas (a mesa familiar, o instrumento musical, a natureza...) que não são meros meios para determinados fins, senão fins em si mesmos. Que não são elementos que podem ser colocados ao serviço de qualquer propósito, mas que reservam um propósito próprio. São coisas com que nos comprometemos e que remetem a um contexto social, cultural e ecológico. São coisas profundas, vale dizer, coisas cujos traços são todos, ou na sua maioria, significativos. E são, em resumo, coisas que reconhecemos e respeitamos em seu próprio direito (cf. Borgmann, 1984, p. 193). 
Certamente, sempre é possível tratar algumas dessas coisas como meros meios:

Quando olhamos tecnologicamente para uma lareira pré-tecnológica, separamos da plenitude dos seus traços a função de fornecer calor como a única e finalmente significativa. Todos os outros traços são considerados então como parte da maquinaria e, estando sujeitos à lei da eficiência, tornam-se dependentes e indefinidamente mutáveis. A visão tecnológica de uma comida revela um agregado de sabores, texturas e caraterísticas nutritivas. Só elas retêm significação estável [...] Analogamente, quando olhamos para uma árvore vemos certa quantidade de madeira ou fibra de celulose; os espinhos, os ramos, a cortiça e as raízes são resíduos. Uma rocha é 5 por cento de metal e o resto é lixo. Um animal é visto como uma máquina que produz tanto de carne. Qualquer uma das suas funções que não serve para esse propósito é indiferente ou incômoda (Borgmann, 1984, p. 192).

E nisso consiste, precisamente, a atitude tecnológica: em que o universo humano perde cada vez mais coisas e práticas "focais", para passar a ser constituído apenas por dispositivos que se produzem, que se usam ou se consomem. Um universo em que não apenas os objetos naturais (como uma planta) ou artificiais (como um ventilador), mas também os objetos sociais e culturais, como o governo ou a educação, são levados em consideração tão somente como meios para fins circunstanciais. Esse universo está dividido em dois âmbitos: o do labor (labor) e o do lazer, uma divisão que espelha aquela entre a maquinaria do artifício e o produto que ele fornece.

À diferença do trabalho (work) tradicional, que estava inserido numa rede social e cultural e que dava sentido à vida do homem trabalhador orientando-o na natureza, na cultura e na sociedade, o labor tecnológico se reduz à produção e manutenção das maquinarias que fornecem os artifícios. Ou então, à produção de artifícios como meios de lazer. Este último, à diferença do prazer que eleva, refina ou enobrece a vida humana (quer se trate de uma leitura, do prazer de uma refeição entre amigos ou da contemplação de uma bela paisagem), se reduz ao consumo indefinido de produtos tecnológicos, ficando cada vez mais dissociado de qualquer preocupação com a excelência da vida pessoal.

A vida conforme o paradigma tecnológico, continua Borgmann, tem um glamour que explica em parte a sua propagação. A tecnologia, como já foi lembrado, prometenos alívio de tarefas penosas, esperança de termos uma relação mais rica com o mundo graças à afluência de dispositivos; ela responde à nossa impaciência com coisas que exigem cuidado e reparação, ao nosso desejo de fornecer a nossos filhos o melhor desenvolvimento, e à vontade de nos afirmarmos na existência adquirindo bens que inspiram respeito. Mas tudo isso vai acompanhado de sentimentos de perda, de pena e 
uma espécie de traição (a um outro tipo de vida), pois as realizações que representavam libertação "parecem ser contínuas com a procura de frívola comodidade”. Dá-se inclusive uma sensação de impotência, pois tudo ocorre como se os instrumentos tivessem acabado por definir os fins.

Fins gerais abstratos - saúde, segurança, comodidade, nutrição, abrigo, mobilidade, felicidade, e assim por diante - tornam-se altamente relativos a instrumentos. O desejo de se locomover torna-se desejo de possuir um automóvel; a necessidade de se comunicar torna-se necessidade de se possuir serviço telefônico; a necessidade de comer torna-se necessidade de uma geladeira, um fogão, e um adequado supermercado (Winner apud Borgmann, 1984, p. 62).

Embora a sensação do ser humano seja a de estar sutilmente preso ao mundo tecnológico (ainda que não pareça mais imaginável viver sem seus produtos), Borgmann não acha que o homem seja simplesmente arrastado pela tecnologia. Já foi mencionado que Borgmann rejeita as teorias substancialistas. Para ele, o que existe é uma certa cumplicidade, ou "implicação", do homem com a tecnologia (Borgmann, 1984, p. 105). Com outras palavras: temos responsabilidade pela manutenção do modo de vida tecnológico, que nos fascina em razão do glamour antes mencionado. É verdade que as circunstâncias sociais favorecem a manutenção e o progresso da tecnologia como paradigma: a desigualdade social os favorece porque cada um aspira a ter o que outros já têm. Mas é verdade, aponta Borgmann, que nem sequer a riqueza dá ao homem poder sobre a tecnologia, pois esta constitui uma cultura, um horizonte em função do qual são tomadas todas as decisões e, nesse sentido, os mais abastados estão tão sujeitos a seu padrão quanto os mais pobres. Nada disso implica para Borgmann a crença de que a tecnologia constitua uma fatalidade.

As tentativas de diagnosticar e corrigir o rumo da sociedade tecnológica sofrem, para nosso autor, do defeito de pressupor aquilo que querem emendar. Para começar, a "promessa da tecnologia" está em consonância com os ideais de liberdade, igualdade e auto-realização próprios da democracia liberal, a qual foi sendo conquistada de acordo com o paradigma tecnológico. A política funciona, para Borgmann, como "metadispositivo" (meta-device) da sociedade tecnológica. E as teorias filosóficas sobre a sociedade justa (como as de J. Rawls e J. Habermas), ao deixarem de lado a questão da "vida boa" para limitarem-se a fundamentar a justiça, subestimam a singularidade da relação meios-fins no paradigma tecnológico e ignoram o quanto dependem dele (cf. Borgmann, 1984, p. 95 e ss.).

A análise da tecnologia está, no livro de Borgmann, em função de uma proposta de reforma, que não deve ser entendida como reforma na tecnologia, mas como reforma 
da tecnologia. Uma reforma que parta do reconhecimento do "paradigma da tecnologia" e da importância daquilo que ele vai nos fazendo perder: coisas e práticas "focais". A argumentação em favor de uma tal reforma não pode ser demonstrativa, à maneira das ciências, nem tampouco paradigmática, como o foi a descrição do paradigma tecnológico, mas dêitica ou "mostrativa", baseada naquelas experiências de coisas que possuem valor e direito de existir em si mesmas (e não como meros meios) e no testemunho que se pode dar delas. A explicação dêitica não é concludente (cogent), mas apelativa, e pode ser sempre contestada (cf. Borgmann, 1984, cap. 21). Conforme a tradição fenomenológica, ${ }^{\mathbf{1 7}}$ Borgmann espera que as suas palavras despertem no leitor a experiência, a lembrança e o desejo daquelas coisas e práticas que podem "centrar" e orientar a vida humana, convencendo-se assim da necessidade e possibilidade de se contrapor à tendência do universo tecnológico.

A reforma proposta apela expressamente para restabelecer a importância da questão da "vida boa", aparentemente eliminada na tecnologia (ou melhor, resolvida a seu modo) e contornada pelas teorias éticas liberais. Sem considerar o que pode dar nobreza, dignidade, excelência à vida humana, não há, segundo Borgmann, possibilidade de justificar qualquer ação face ao império da tecnologia. Se este último é o âmbito da extensão indefinida dos meros meios, do labor que conduz ao consumo, da relação não engajada com os artifícios, a reforma deve orientar-se pelo restabelecimento daquelas experiências que podem constituir-se em fins em si mesmas para as pessoas e comunidades. A cultura da mesa, o caminhar, a pesca, a prática da música, as festas, a vivência da natureza ainda intocada etc., são exemplos de "interesses focais" (focal concerns) a serem recuperados. Essa recuperação não significa rejeitar de forma genérica a tecnologia (coisa, por outro lado, impossível), mas reduzi-la à condição das práticas "focais". "Uma prática focal gera uma atitude inteligente e seletiva para com a tecnologia. Ela conduz a uma simplificação e perfeição da tecnologia contra o pano de fundo do interesse focal da pessoa, e a um uso reflexivo dos produtos tecnológicos no centro da prática da pessoa”. Assim, um homem pode gostar de correr,

[...] mas ele não vai correndo a todo lugar aonde quer ir. Para ir trabalhar, ele dirige um carro. Ele depende desse artefato tecnológico e de toda a correspondente maquinaria de produção, serviço, recursos e estradas. Certamente... irá querer que o carro seja um artefato tecnológico tão perfeito quanto seja possível: seguro, confiável, fácil de operar, livre de manutenção. Dado que os corredores

17 O fenomenólogo Max Scheler disse, em algum lugar, que um escrito fenomenológico é um convite a olhar numa certa direção, a fim de enxergar o que o autor descreve. 
desfrutam profundamente do ar, das árvores, e dos espaços abertos que tornam agradável sua corrida, e dado que o vigor e a saúde humanos são essenciais para seu empreendimento, seria coerente da parte deles querer um carro benigno para o ambiente, que seja livre de poluição e que requeira um mínimo de recursos para a sua produção e operação. Dado que os corredores se expressam mediante a corrida, eles não iriam necessitar do brilho, do tamanho ou da novidade em seus veículos. [...] Os corredores apreciam calçados que sejam leves, firmes e que absorvam o impacto. Este tipo de calçado permite que a pessoa se mova mais rapidamente, que vá mais longe e mais fluidamente. Mas os corredores não iriam querer ter esses movimentos mediante uma motocicleta, nem iriam querer, tampouco, meramente obter o benefício fisiológico de tal movimento corporal mediante uma esteira rolante (Borgmann, 1984, p. 221).

De maneira análoga, é possível conceber uma utilização da tecnologia e dos seus aperfeiçoamentos, na medida em que permita e favoreça qualquer prática focal que tenhamos escolhido. Vista assim, a tecnologia realça o caráter de tais práticas, em vez de soterrá-las, como acontece quando se vive em cumplicidade com ela.

O princípio da reforma proposta por Borgmann consiste, pois, em elevar os assuntos de interesse focal a fins em relação aos quais todos os recursos tecnológicos são meios. Isso pode e deve fazer-se não apenas em nível pessoal e familiar, mas também em nível da comunidade nacional, e em função de conceber a "vida boa" como uma vida de excelência definida, não pela posse de dispositivos ou o consumo de produtos (em resumo, pelo "padrão de vida”), mas pela qualidade de vida. Esta última não se mede pela afluência material, mas pela riqueza de engajamento de que os seres humanos sejam capazes. Em nível social, a proposta de Borgmann inclui sugestões de reformas econômicas que fomentem a indústria de pequeno porte, "labor-intensiva" (a qual permitiria recuperar a função dignificadora do trabalho), remodelação das cidades, resgatando espaços para usos “focais”, bem como a expectativa de que, se a sua mensagem for compreendida, os cidadãos irão se sensibilizar para a questão da justiça social. Isto significa que a redução do consumo por parte daqueles empenhados em levar uma vida orientada pelas coisas e não pelos artifícios tecnológicos, iria acompanhada pela vontade de que a situação material da classe baixa (e dos povos mais pobres) fosse melhorada, a fim de que todos pudessem ter a oportunidade de viver uma vida com sentido (cf. Borgmann, 1984, p. 244, e ss.). 


\section{A perspegtiva grítica de Abdrew Feenberg}

Um terceiro enfoque da tecnologia está representado pela obra de Feenberg, Transforming technology (2002). ${ }^{\mathbf{1 8}} \mathrm{O}$ autor propõe uma interpretação da tecnologia que, como a de Borgmann porém por diferentes razões, rejeita tanto a visão instrumentalista quanto a substancialista. Trata-se de um enfoque que prolonga as análises da Escola de Frankfurt (em particular, Marcuse), aspirando a "reconstruir a idéia de socialismo com base numa radical filosofia da tecnologia”.

A tecnologia, concorda Feenberg, é um fenômeno tipicamente moderno. Mais ainda, ela constitui a "estrutura material" da Modernidade. Mas a tecnologia, no argumento do autor, não é um mero instrumento neutro, pois ela encarna valores antidemocráticos provenientes da sua vinculação com o capitalismo e manifestos numa cultura de empresários, que enxerga o mundo em termos de controle, eficiência (medida pelo proveito alcançado) e recursos. Os valores e interesses das classes dominantes estão inscritos no próprio desenho dos procedimentos e máquinas, bem como nas decisões que os originam e mantêm. Por outro lado, a tecnologia não constitui uma entidade autônoma nem um "destino". ${ }^{19}$ A conquista da natureza que ela encarna não é um evento "metafísico" (como quer Heidegger, 1997 [1954]), mas começa como dominação social. O controle da natureza é indissociável do controle de seres humanos por outros, o que se traduz em fenômenos também típicos da nossa época, como a degradação do trabalho, da educação e do meio ambiente. Por ser a manifestação de uma racionalidade política, a tecnologia não pode ser modificada mediante reformas morais ou atitudes espirituais (como quer Borgmann, por exemplo). O que se requer é uma modificação cultural proveniente de avanços democráticos. Feenberg defende uma posição "não determinista”, cujas teses básicas seriam:

1. O desenvolvimento tecnológico está sobre-determinado tanto por critérios técnicos quanto sociais de progresso, podendo, por conseguinte, bifurcar-se em qualquer uma de diversas direções, conforme a hegemonia que prevalecer.

2. Enquanto as instituições sociais se adaptam ao desenvolvimento tecnológico, o processo de adaptação é recíproco, e a tecnologia muda em resposta às condições em que se encontra tanto quanto ela as influencia (Feenberg, 2002, p. 143).

18 Edição revisada de Critical theory of technology (1991). Feenberg é professor da Universidade de São Diego (EUA) e autor de Alternative modernity: the technical turn in philosophy and social science (1995) e estudos sobre Marcuse e Heidegger.

19 Ela é, antes, “um processo ambivalente de desenvolvimento, suspenso entre diferentes possibilidades", e "um cenário de luta” (Feenberg, 2002, p. 15). 
Um elemento crucial para se empreender a modificação da tecnologia consiste em reconhecer a distinção básica entre os que comandam e os que obedecem nesta civilização tecnológica, em que o poder tecnológico tornou-se a principal forma de poder, substituindo as formas baseadas antigamente em outras justificações, como o nascimento ou a religião. ${ }^{20} \mathrm{O}$ poder é, por sua vez, exercido em forma de administração e de controle estratégico das atividades sociais e pessoais. Feenberg destaca, desde o início de sua análise, a "autonomia operacional" dos administradores (capitalistas e tecnocratas), isto é, a sua liberdade para tomar decisões independentes sem considerar os interesses dos agentes subordinados nem da comunidade, ignorando também as conseqüências ambientais. Para além dos objetivos circunstanciais, a "autonomia operacional" tem como meta-objetivo a sua indefinida preservação, o que é garantido pela racionalidade intrínseca à tecnologia, uma racionalidade que se ampara no caráter aparentemente absoluto da justificação pela eficiência.

Com efeito, as decisões tecnológicas parecem adotadas em função da eficiência, que é o valor característico dessa dimensão da vida humana. No entanto, o critério de eficiência não basta para determinar o desenvolvimento tecnológico, pois a própria eficiência pode ser diferentemente definida conforme diversos interesses sociais. "Os objetos técnicos são também objetos sociais" e o desenvolvimento tecnológico "é um cenário de luta social". Comparando o desenvolvimento tecnológico com o uso da linguagem, em que a gramática condiciona o significado, mas não decide o propósito, Feenberg afirma que existe um código social da tecnologia, que associa eficiência e propósito. ${ }^{21}$

Naturalmente, as partes de uma invenção, tal como a linha de montagem, têm uma coerência técnica própria que não depende em absoluto da política ou de relações de classe. A tecnologia não se reduz, neste exemplo, a relações de produção, nem o conhecimento técnico a ideologia. O primeiro termo em cada um desses pares tem a sua própria lógica; a tecnologia deve realmente funcionar. Mas não é meramente porque um artefato funciona que é escolhido para o desenvolvimento em vez de outras configurações igualmente coerentes de elementos

20 Na sua análise do poder social, Feenberg combina idéias de Certeau, Marcuse e Foucault.

21 Reciprocamente, pode-se falar do "código técnico" de um sistema social como o capitalismo. O “código", ou seja, os padrões de organização dos elementos, responde ao imperativo de hegemonia do capitalismo. Tratar-se-ia de um caso do que Feenberg denomina "distorção formal" (formal bias), vale dizer, aquela que não se reconhece nos elementos combinados, mas na sua combinação. No caso das realizações tecnológicas, a distorção que apresenta como "neutro" o que é ideológico só pode ser denunciada revelando o contexto e a evolução histórica. Esse é o propósito da Teoria Crítica. Cf. Feenberg, 2002, p. 82. 
técnicos. O caráter social da tecnologia reside não na lógica do seu funcionamento interno, mas na relação dessa lógica com um contexto social. [...] A linha de montagem tão somente aparece como um progresso técnico porque estende a classe de racionalidade administrativa de que o capitalismo já depende. Poderia não ser percebida como um avanço no contexto de uma economia baseada em cooperativas de operários em que a disciplina de trabalho fosse auto-imposta em vez de imposta desde cima (Feenberg, 2002, p. 79).

Sob o código técnico do capitalismo, a eficiência tem como mais importante medida o lucro, que se realiza por meio da venda de mercadorias. A ele se subordina toda outra consideração e por ele são ignoradas outras preocupações (como a qualidade de vida, a educação, a justiça social ou a proteção do meio ambiente), reduzidas a meras "externalidades". ${ }^{22}$ Mas a eficiência poderia ser diferentemente concebida num outro código social que respondesse a exigências da vida humana hoje não realizadas e que aparecem em forma de reivindicações econômicas e morais (igualdade de oportunidades, proteção aos descapacitados, satisfação no trabalho, direito ao lazer...). Procedimentos e artefatos eficientes não precisam fazer abstração de tudo quanto não se refira ao lucro, ao poder, ao consumo e ao "padrão de vida".

O capitalismo (e o socialismo burocrático), sustenta Feenberg, fomenta realizações tecnológicas que reforçam as estruturas sociais hierárquicas e centralizadas e, de modo geral, o controle "desde cima", em todos os setores da vida humana: trabalho, educação, medicina, lei, esportes, meios de comunicação etc. Existe, em resumo, uma "mediação técnica generalizada", ao serviço de interesses privilegiados, que reduz em todas as partes, em nome da eficiência, as possibilidades humanas, impondo em todo lugar, como medidas óbvias, a disciplina, a vigilância, a padronização. Reciprocamente, a mediação de determinados interesses sociais faz que as realizações tecnológicas sejam atualmente abstratas e descontextualizadas. Trata-se de objetos e procedimentos que não parecem pertencer a nenhum mundo cultural em especial, e de sujeitos que se compreendem a si mesmos pela sua função e se acreditam livres de responsabilidade quanto às conseqüências das suas atividades. São esses, argumenta Feenberg, "momentos" típicos da reificação social que a tecnologia representa (cf. Feenberg, 2002, p. 178). No entanto, na opinião de Feenberg, é precisamente a percepção (sempre possível) dessas limitações e deformações (e as correspondentes potencialidades suprimidas)

$22 \mathrm{O}$ acréscimo de eficiência, nos moldes atuais, não raramente "exige" a descapacitação do operário, reduzido a apêndice de máquinas ou processos, ou até mesmo a sua absoluta substituição pelas maquinarias automatizadas. A educação reduz-se a um "investimento", conforme as "exigências" do mercado, e assim por diante. 
o que pode estimular movimentos políticos transformadores. Essa esperança do autor fundamenta-se no fato de que a hegemonia do "código técnico" do capitalismo não pode impedir que haja iniciativas contrárias. Feenberg afirma que a sociedade pode ser comparada, não apenas a uma máquina, mas a um jogo, e que desde este ponto de vista, as estratégias de domínio que preservam a "autonomia operacional" são contestadas por táticas dos dominados que aproveitam suas "margens de manobra”.

Assim como a autonomia operacional serve como a base estrutural da dominação, um diferente tipo de autonomia é conquistado pelos dominados, uma autonomia que opera com o "jogo" no sistema para redefinir e modificar suas formas, ritmos e propósitos. Denomino "margem de manobra" essa autonomia reativa. Pode ser usada para uma diversidade de propósitos em organizações tecnicamente mediadas, incluindo controlar a marcha do trabalho, proteger colegas, improvisações produtivas não autorizadas, inovações e racionalizações informais, e assim por diante (Feenberg, 2002, p. 84).

Do mesmo modo como as táticas contestadoras são possíveis porque a evolução da tecnologia não pode ser absolutamente controlada, o resultado da contestação tampouco pode ser previsto. Às vezes, os resultados das táticas dos dominados são reabsorvidos pela lógica dominante. Outras vezes, no entanto, as modificações podem se estabelecer. ${ }^{23}$ A contestação do rumo autoritário da tecnologia não seria possível, no entanto, se a tecnologia não fosse ambivalente, podendo ser instrumentalizada em função de diferentes projetos políticos. Como argumenta Feenberg, "a tecnologia é em grande medida um produto cultural e, assim, toda ordem tecnológica é um ponto de partida potencial para desenvolvimentos divergentes, conforme o ambiente cultural que lhe dá forma". Mais ainda, para ele, é possível perceber na tecnologia uma "dupla instrumentalização" que sugere a possibilidade de que ela venha a ter um diferente rumo. A tecnologia constitui basicamente uma atitude ou orientação com relação à realidade ("instrumentalização primária"). No entanto, ela é também um modo de ação ou realização no mundo social. A “essência da tecnologia” reside na união (dialética) entre ambos níveis de instrumentalização (cf. Feenberg, 2002, p. 175). ${ }^{\mathbf{2 4}}$

23 Feenberg exemplifica as possibilidades de um outro desenvolvimento da tecnologia, analisando o computador (instrumento de controle ou de comunicação) e propondo a cidade (lugar do diálogo), e não a fábrica (servida pela automação), como modelos de uma educação estimulada pelos avanços tecnológicos. Cf. Feenberg, 2002, cap. 4, e 5. 24. Um serrote, como instrumento técnico, não existe sem a atividade de serrar, ou a carpintaria, como atitude humana. No entanto, a forma concreta de um serrote particular, sem valor simbólico etc., não se compreende apenas pela sua função (considerada em abstrato), mas pelo contexto sociocultural. Gf. Feenberg, 2002, cap. 4. e 5 . 
A mudança social sugerida necessita, certamente, de critérios de progresso em direção da realização humana. Feenberg os resgata da "tradição humanista", entendendo que a sociedade progride na medida em que aumenta a capacidade das pessoas para assumir responsabilidade política, em que se fomenta a universalidade do ser humano (contra toda forma de discriminação), em que se permite a liberdade de pensamento, em que se respeita a individualidade e se estimula a criatividade (cf. Feenberg, 2002, p. 19-20).

Ora, essa transformação orientar-se-ia para que tipo de sociedade? Assumindo a lição histórica representada pelo fracasso dos sistemas comunistas (especialmente, em termos de eficiência econômica, assim como em promover a democracia), mas atento também à desconfiança de economistas (como J. Stiglitz) com relação à economia de mercado, Feenberg propõe uma nova noção de socialismo como meta de uma transformação cultural. Retomando criticamente as idéias de Marx e da Escola de Frankfurt, nosso autor propõe interpretar o socialismo como não apenas uma questão política, ou uma etapa a ser alcançada mediante uma revolução, entendida como episódio histórico, mas como uma transição gradual para outro tipo de civilização em que se desenvolvam determinadas potencialidades humanas hoje negadas.

O socialismo significaria "uma sociedade que privilegia bens específicos que não são de mercado e emprega uma regulação e uma propriedade públicas substancialmente mais extensas que as existentes nas sociedades capitalistas para obtê-los". Um tal socialismo não estaria "em imediata oposição" ao capitalismo, mas representaria uma possível evolução a partir dos atuais estados de bem-estar social.

A transição para o socialismo pode ser identificada pela presença de fenômenos que, tomados separadamente, parecem economicamente irracionais ou administrativamente não efetivos desde o ponto de vista da racionalidade tecnológica capitalista, mas que juntos iniciam um processo de mudança civilizatória (Feenberg, 2002, p. 148).

Feenberg cita como exemplos de medidas que poderiam "pôr em movimento" um tal processo a extensão da propriedade pública, a democratização da administração, a ampliação do tempo de vida dedicado à aprendizagem para além das necessidades imediatas da economia, e a transformação das técnicas e do treinamento profissional para incluir um leque cada vez maior de necessidades humanas no código técnico. A adoção dessas medidas poderia servir como índice de avanço social para além do atual capitalismo. 
De resto, Feenberg admite antecipadamente que não está esboçando um processo de implementação fácil, nem sequer provável. Se alguém considerasse que esse exercício de imaginação é inútil, o autor revidaria:

Estas reflexões são estritamente condicionais. É impossível predizer o futuro, mas pode-se tratar de esboçar uma senda coerente de desenvolvimento que conduziria a um resultado propriamente socialista em circunstâncias favoráveis. A discussão está assim endereçada não à probabilidade de um tal resultado, mas à sua possibilidade. [...] estabelecer essa possibilidade não é apenas um ato de fé política; tem também uma função heurística: é um modo de quebrar a ilusão de necessidade de que o mundo quotidiano está revestido (Feenberg, 2002, p. 150).

\section{Reflexões Finais}

A filosofia é notoriamente difícil de ser definida. Estou convencido de que se deve entendê-la como uma atitude consistente em pensar de maneira crítica e rigorosa para viver mais responsavelmente. Como tal, a filosofia é suscitada por tudo aquilo diante o que precisamos "saber ao quê nos atermos", como dizia Ortega y Gasset (1965). Qual é a contribuição dos três enfoques da tecnologia para "saber ao quê nos atermos" em relação a ela?

Bunge representa, de maneira talvez insuperável pela clareza e amplitude de tratamento, a confiança na tecnologia como forma de aprimorar a existência humana. Embora não acredite na sua neutralidade, e precisamente por isso, deposita na tecnologia a esperança de superar, tanto os modos de vida atrasados ou deficientes, como os problemas causados pelos procedimentos e artefatos nocivos. Isso depende, é claro, da política que impulsiona a tecnologia, e da ética que deveria inspirá-la, para as quais Bunge, como foi mencionado, tem propostas (cf. Bunge, 1989). Frente a outros tratamentos da tecnologia, o de Bunge destaca-se pela riqueza do exame, sempre rigoroso, que abrange desde os detalhes do raciocínio tecnológico até o discernimento dos diversos tipos de tecnologia, incluída a crítica do que considera pseudo-tecnologia (cf. Bunge, 1985a, cap. 5 e 6). Trata-se, em seu conjunto, de uma filosofia otimista, herdeira declarada dos ideais do Iluminismo e do liberalismo clássico, formulada com uma nitidez que a torna convincente.

É claro que seus méritos não excluem motivos de dúvida ou preocupação. Sua caracterização como tecnológica de atividades tais como a medicina, a pedagogia ou a administração pode provocar certo mal-estar, porém é mister lembrar que Bunge está querendo frisar a necessidade de que elas sejam executadas com base no conhecimento 
científico, sem eliminar, no entanto, certa dose de saber vulgar, nem negar o papel da capacidade, do talento ou da experiência (como ele ocasionalmente tem esclarecido). Mais problemática ainda pode resultar a proposta de ver na tecnologia a ação racional por excelência, se levarmos em consideração as críticas de Hannah Arendt (1983) e de Habermas (1968) à identificação da ação com a fabricação (đñüôôåéí e điéåúú, na sua denominação grega), identificação em que aqueles autores viam uma ameaça ao reconhecimento da especificidade da ação ética e política. Não obstante, a oposição de Bunge à tecnocracia e sua insistência em que os cidadãos não devam consultar cientistas e expertos, nas questões políticas, porém decidir por si mesmos, leva a pensar que não pretende negar aquela especificidade.

Cabe, contudo, criticar no otimismo bungeano a sua falta de percepção da capacidade que tem a tecnologia de desestruturar as culturas em que se introduz. Bunge parte da pressuposição, típica do Iluminismo, de que toda tradição equivale a atraso e de que toda cultura não científica é de algum modo defeituosa. A absoluta confiança nos ideais iluministas impede Bunge, ao que parece, de apreciar ou de imaginar aspectos positivos nas culturas não científicas, assim como de perceber limitações do Iluminismo. Nesse sentido, são úteis trabalhos como os de Ladrière (1979) e Lacey (1999).

A interpretação de Albert Borgmann tem os méritos e as dificuldades típicos da fenomenologia. A descrição da maneira em que a tecnologia perpassa, define e dirige a nossa existência é por demais "reveladora", o que constitui, como foi dito, o propósito declarado do autor. ${ }^{25}$ A abordagem dêitica praticada por Borgmann transmite ao leitor a vivência, não apenas do que pode ser conceitualizado na tecnologia, mas também daquilo que nela resulta inefável, e que toda teoria parece dissipar. Segundo ele, todas as teorias deixam de detectar o fato da nossa "cumplicidade" com a tecnologia, uma "implicação" que faz com que sejamos, no fundo, responsáveis pelo seu aparente domínio sobre nós. É importante notar que Borgmann é consciente de que a sua análise vale, sobretudo, para a maneira como a tecnologia modela os países altamente industrializados como o seu (os Estados Unidos), e que não aborda, por serem "demasiado complexos", casos ou aspectos do avanço tecnológico como o poderio bélico, a exploração do espaço, ou a fome no Terceiro Mundo (cf. Borgmann, 1984, p. 114). De qualquer modo, Borgmann está convencido de que a abordagem fenomenológica exibe, conforme a sua índole, a verdadeira essência da vida tecnológica.

25 A noção de "paradigma do dispositivo" (device paradigm), que permite ver, como uma unidade, uma série de fenômenos aparentemente heterogêneos, desde um aparelho de televisão até a política, é um verdadeiro achado, conforme comenta M. Stanley. Cf. Stanley, 1988, p. 15 . 
Ora, é difícil evitar a impressão de que a interpretação de Borgmann subestima o peso dos fatores e circunstâncias sociais, particularmente quando rejeita a visão marxista da tecnologia por considerar que ela "desculpa as pessoas" por entregar-se à vida tecnológica. Um crítico (de resto admirador da sua obra) observa que Borgmann parece pensar apenas no marxismo vulgar. ${ }^{26}$ Nosso autor defende-se alegando que, mesmo nas suas versões mais sofisticadas, é sempre possível optar por uma leitura mais "científica" ou mais "moral" da doutrina de Marx, ou seja, pela ênfase na força das estruturas sociais, ou pelo apelo à possibilidade humana de modificá-las. Borgmann acredita que até mesmo os marxistas mais sensíveis à problemática da liberdade humana (ele menciona nomes como os de Marcuse, Leiss e Habermas) acabam apresentando um quadro de dominação social em que os sujeitos dominados nem sequer podem advertir a sua capacidade de produzir mudanças. A essa perspectiva, Borgmann contrapõe sua tese de que, se na superfície todos parecemos presos à tecnologia, a um nível "profundo" nos sabemos livres para adotarmos uma atitude diferente para com ela. Isso se manifestaria, em sua opinião, na ambivalência com que enfrentamos a tecnologia, oscilando entre o fascínio e a desconfiança (cf. Borgmann, 1988, p. 35). Por conseguinte, se o homem não é um joguete da tecnologia (nem das estruturas sociais), deve ser possível mobilizá-lo para que reaja ao que o prejudica. E a explicação marxista de que os oprimidos não reagem por causa do peso "irresistível" do sistema capitalista é, para Borgmann, insuficiente. A verdadeira razão reside, para ele, na universal "cumplicidade" para com a tecnologia, e a oportunidade de uma saída para essa situação está em mobilizar as pessoas. A isso apontam o "discurso dêitico" e a força do exemplo ao cultivar os "interesses focais".

A defesa de Borgmann não é convincente, e a sua fraqueza se torna ainda mais nítida quando se faz a leitura da sua obra, como em nosso caso, desde países em que os benefícios e prejuízos da tecnologia estão, mais claramente que no Primeiro Mundo, vinculados à desigualdade social, e onde a possibilidade de boa parte da população alterar sua relação com a tecnologia de que chega a dispor é nula. ${ }^{\mathbf{2}}$. Por outra parte, é em nossos países que os "interesses focais" são (ainda) mais cultivados do que nos países industrializados. ${ }^{\mathbf{2} 8}$ Em certo modo, a exortação de Borgmann é supérflua para nós e,

26 S. Carpenter (1988, p. 9 e ss.). Para este crítico, mais importante que a tecnologia como elemento modelador da vida moderna, foi a economia de mercado e a monetarização da sociedade, a vida "estabelecida numa base de commodities", e a dissociação entre a vida cívica e o âmbito dos negócios. Compartilho dessa opinião.

${ }_{27}$ Borgmann reconhece que suas propostas supõem uma vida próspera. Cf. Borgmann, 1988, p. 223.

28 Penso, por exemplo, que em um país como o Brasil, a comida familiar, em vez do apressado fast food individual, é ainda o hábito da maior parte da população, assim como a tendência e o gosto das festas e da música em grupos. 
temo, inócua para os países como o dele. Somos levados a pensar que há uma boa dose de ingenuidade em sua expectativa de que o cultivo de "interesses focais" e o entusiasmo dos que o façam irá propagar-se pelo resto de uma sociedade próspera como a dele, provocando inclusive o desejo de que a igualdade social se realize nas outras regiões do mundo. Borgmann comete o erro de esperar de um enfoque (o fenomenológico) destinado a permitir compreender as vivências, que sirva para explicá-las e para mudar as estruturas sociais de que derivam. Por princípio, isso não é possível. ${ }^{29}$

O reconhecimento do caráter sociopolítico da tecnologia é, como vimos, o aspecto característico da análise de Feenberg, que deve compartilhar, imagino, os receios frente ao otimismo liberal de Bunge (embora não se refira a ele), ${ }^{3 \circ}$ e critica Borgmann, entre outras coisas, por afirmar que a tecnologia contemporânea é "perfeita a seu modo" (cf. Feenberg, 2002, p. 9). A contribuição mais importante de sua análise parece-me ser a crítica ao argumento de eficiência como justificativa do caráter e das modalidades da tecnologia existente. Perceber que os produtos, os mecanismos e as soluções tecnológicas não respondem a uma eficiência a eles inerente, mas a uma eficiência constituída, parcialmente, por interesses sociais, é menos fácil do que se pensa, numa sociedade em que a mera preferência pela eficiência alcançou o caráter de obviedade. É também relevante, no meu entender, que Feenberg não permaneça numa denúncia genérica das realizações tecnológicas possibilitadas pela economia capitalista, mas aponte para a sua possível instrumentalização em direção a um modo de vida diferente. Tal é o caso do capítulo em que mostra a possibilidade de que o computador e a internet não sejam necessariamente fatores de descapacitação, automatismo e alienação humanos, mas se convertam em meio de iniciativa, inteligência e comunicação. Não raramente, as análises inspiradas pelo marxismo alimentam atitudes genericamente negativas com relação à tecnologia originada pela atual estrutura social mundial.

Já quanto às iniciativas sociais que Feenberg sugere para promover uma transição ao socialismo, ${ }^{31}$ o autor é consciente, como foi comentado, de que se trata de possibilidades cuja implementação está longe de ser fácil. Feenberg conjectura que a sua viabilidade pode ser alcançada conseguindo a colaboração das elites técnicas, pertencentes aos "estratos médios" da sociedade. Com efeito, boa parte das reformas por ele

29 Talvez a confiança de Borgmann na força das práticas "focais" e do discurso "dêitico" como fatores de mobilização repouse nas suas convicções religiosas (ele se assume como católico), mais do que na força dos seus argumentos.

3o Por outro lado, há uma coincidência entre Bunge e Feenberg no que diz respeito a que, para ambos, a tecnologia não é neutra, mas dependente de decisões políticas.

31 Naturalmente, excede os propósitos deste trabalho apreciar os méritos da tese de Feenberg de que a passagem para o socialismo não deve ser entendida necessariamente como uma revolução política, mas como um projeto de nova civilização. 
reivindicadas tem a ver com a democratização da administração, em todas as ordens da vida, e a supressão da diferença social entre trabalho manual e intelectual. As reformas implicam "um ataque geral à hegemonia tecnocrática", pois todas as instituições estão hoje tecnologicamente mediadas e conduzidas autoritariamente. A modificação, mesmo que paulatina, da situação atual só poderá ocorrer caso as elites profissionais acedam a colaborar, o que não pode ser conseguido pela violência ou por decisão administrativa. Embora as elites técnicas e culturais não tenham sido consistentemente solidárias das revoluções (francesa e russa), comenta Fenberg, a sua atitude em maio de 1968, na França, sugere que podem circunstancialmente apoiar uma transição ao socialismo. "Por conseguinte, a idéia de uma aliança para reorganizar o trabalho coletivo não é meramente uma vã especulação, mas ressoa como uma importante experiência histórica" (Feenberg, 2002, p. 160). De qualquer modo, a análise da tecnologia realizada por Feenberg tem, sem dúvida, o caráter que o autor lhe atribui, ou seja, possui a "função heurística" de "quebrar a ilusão de necessidade de que o mundo quotidiano está recoberto".

Aúltima afirmação talvez caiba aos três autores apresentados. Pode parecer pouco, face aos desafios que a tecnologia nos coloca, porém é indispensável para buscarmos um mundo melhor.

\author{
Alberto Cupani \\ Professor Titular do Departamento de Filosofia do \\ Centro de Filosofia e Ciências Humanas da \\ Universidade Federal de Santa Catarina. \\ Pesquisador do GNPq. \\ cupani@cfh.ufsc.br
}

\begin{abstract}
The philosophical study of technology is rather recent and diversified, according to different theoretical orientations and their corresponding social stances. This heterogeneity notwithstanding, or perhaps due to it, philosophy of technology helps us to acknowledge technology as a dimension of human life, not merely as a historical event. This is what I want to show here by means of presenting three modes of philosophical investigation of technology: Mario Bunge's, Albert Borgmann's, and Andrew Feenberg's. They illustrate, respectively, an analytical point of view, a phenomenological approach, and an examination inspired by the School of Frankfurt. The main purpose of this article is to divulge those investigations, which are not very well known among us. Nevertheless, the article also contains a brief critical judgment of them.
\end{abstract}

KeYwords $\bullet$ Philosophy of technology. Mario Bunge. Albert Borgmann. Andrew Feenberg. 


\section{REFERÊNGIAS BIBLIOGRÁFICAS}

Arendt, H. A condição humana. Rio de Janeiro, Forense, 1983 [1958].

Borgmann, A. Technology and the character of contemporary life. A philosophical inquiry. Chicago/Londres, The University of Chicago Press, $19^{8} 4$.

. Reply. In: Durbin, P. T. (Ed.). Technology and contemporarylife. Dordrecht, Reidel, 1988. p. 29-44.

Bunge, M. La investigación científica. Barcelona, Ariel, 1969.

. Treatise on basic philosophy. Dordrecht, Reidel, 1984-1989. 8 v.

. Epistemologia. São Paulo, T. A. Queiros/Edusp, 1980.

. Seudociencia e ideología. Madri, Alianza, 1985a.

Treatise on basic philosophy. Dordrecht, Reidel, 1985b. Tomo 7: Philosophy of science and technology.

Dordrecht, Reidel, 1989. Tomo 8: The good and the right.

Carpenter, S. R. Adiscussion. In: Durbin, P. T. (Ed.). Technology and contemporarylife. Dordrecht, Reidel, 1988. p. 1-12.

Durbin, P. T. (Ed.). Technology and contemporary life. Dordrecht, Reidel, 1988.

Feenberg, A. Transforming technology. A critical theory revisited. Oxford, Oxford University Press, 2002.

Habermas, J. Theorie und Praxis. Frankfurt, Suhrkamp, 1968.

Heidegger, M. Sein und Zeit. Tübingen, Max Niemeyer, 1967.

. A questão da técnica. Cadernos de tradução, n. 2, Departamento de Filosofia-USP, 1997 [1954].

LACEY, H. Is science value free? Londres, Routledge, 1999.

Ladrière, J. Os desafios da racionalidade. Petrópolis, Vozes, 1979.

Miтcham, C. Thinking through technology. The path between engineering and philosophy. Chicago/Londres, The University of Chicago Press, 1994.

Ortega y Gasset, J. Meditación de la técnica. Madri, Espasa-Calpe, 1965.

Stanley, M. A critical appreciation. In: Durbin, P. T. (Ed.). Technology and contemporary life. Dordrecht, Reidel, 1988. p. 13-28. 